\title{
Application of Radioisotopes in Steel Works*
}

\author{
By Каzио МIYAGAWA, ** Isamu ICHIJIMA, ,* Etsuo NOMURA, ** Hisashi ISSHIKI, ** \\ Isamu MISHIMA,** and Takeji EGASHIRA**
}

\begin{abstract}
Synopsis
The application of radioisotopes in steel works has been summarized below, with main emphasis being placed on tracer application and descriptions being made under headings iron making, refractories, steel making, rolling, and surface treatment.
\end{abstract}

\section{Introduction}

Radioisotopes (RI) recently have come to be used widely at various shops of steel works.

Particularly in the iron making and steel making processes that have to handle high-temperature molten materials, RI are found to be effective applications with respect to problems that would be difficult to solve by conventional procedures.

The applications of RI may be classified broadly as follows:

(1) Tracer application ... Process experiment.

(2) Measurement application ... . . Thickness gauges, moisture gauges, liquid level gauges.

(3) Nondestructive testing application ... Radiography.

(4) Analytical application ... Activation analysis.

(5) Safety device application ... Coke oven interlock system.

RI have the following properties:

(1) RI have the same chemical properties as stable elements.

(2) RI, by constantly emitting radiations that indicate their locations, properties and intensity, allow themselves to be measured easily at distances.

(3) The extremely high detection sensitivity of radiations permits the detection of very small quantities of elements that would be impossible by other means.

(4) The decay characteristic (half-life) of RI varies with individual RI and does not change by temperature, pressure, chemical composition, etc.

By virtue of these properties, RI are extensively used as tracers in process experiment and laboratory work on the movement, diffusion, mixing, dissolution, solidification, abrasion, etc., of substances.

With particular stress placed on tracer application, principal RI application undertaken by this author will be described below in the order of process.

\section{Pig Iron Making}

RI have been in use, since relatively early times, for measuring the distribution of gas, the travelling time of burdens, and the erosion of brick in blast furnaces and for other purposes. Equally prevalent is their use in moisture gauges, level gauges, etc.

\section{Measuring the Travelling Time of Blast Furnace Burdens}

RI have been used to measure the time required for the blast furnace burdens such as iron ore, sinter, and coke to reach the hearth.

Common procedure in determining the travelling time of furnace burdens is to enclose a gamma ray source such as ${ }^{198} \mathrm{Au}$ and ${ }^{60} \mathrm{Co}$ in the burdens, charge them in place at the furnace top, collect samples of the pig iron being tapped, and measure the intensity of radioactivity therein. ${ }^{1)}$

Table 1. Travelling time of blast furnace burdens (Hirohata No. 1 B.F., Jan. 1966)

\begin{tabular}{l|ccc}
\hline Kinds of burdens & $\begin{array}{c}\text { Size } \\
(\mathrm{mm})\end{array}$ & $\begin{array}{c}\text { Travelling time } \\
(\mathrm{hr})\end{array}$ & $\begin{array}{l}\text { timin }) \\
(\mathrm{m})\end{array}$ \\
\hline Iron Ore & 30 & $9^{\circ}$ & $10^{\prime}$ \\
Sinter & 50 & $9^{\circ}$ & $30^{\prime}$ \\
Coke & 40 & $10^{\circ}$ & $30^{\prime}$ \\
\hline
\end{tabular}

Shown in Table 1 is an example of the burden travelling time. It varies with the furnace operating conditions as well as with the furnace size.

Beside this procedure, practice in the Soviet Union ${ }^{2)}$ is to insert radiation detectors into the furnace wall at levels dividing the furnace height into several equal sections, measure the length of time taken by a RI passing the points, and thus determine the state the burdens travel down the furnace.

\section{Studying the Distribution of Gas in the Blast Furnace}

As a hot blast of $1000^{\circ}$ to $1100^{\circ} \mathrm{C}$ is forced into the blast furnace through the tuyeres, it is necessary to ascertain the length of time needed by the blast to travel through the furnace, and how the blast is distributed in the furnace. For this purpose, ${ }^{222} \mathrm{Rn}$ gas was charged through the tuyere peepholes to sample the gas at specified furnace top position, detect radioactivity by proportional counter, and estimate the gas distribution in the furnace by the length of time required for travel through the furnace and by the intensity of radioactivity detected. ${ }^{3)}$

The findings indicate that the gas travelled from the tuyere to the furnace top in short time of one to $10 \mathrm{sec}$, the length of time and the quantity of radioactivity being different between the center and wall of the

* Received May 16, 1969.

** Hirohata Works Laboratory, Fuji Iron \& Steel Co., Ltd., Fuji-cho, Hirohata-ku, Himeji 671-11. 
furnace.

Moreover, what would result from changing the top gas pressure in high top pressure operations was studied to prove that the length of time for travel through the furnace increased as the pressure rose. ${ }^{4)}$

\section{Measuring the Erosion of Hearth Brick}

For blast furnace hearths, carbon brick has recently come into use, drastically augmenting the service life of furnaces and leading to the development of furnaces that turn out over $5000000 \mathrm{t}$ during a single campaign. It would be no exaggeration to say that the life of a blast furnace depends upon the life of hearth provided the shaft and other parts are sturdy enough. As to the erosion of hearth, however, empirical estimation was in practice for some time. In contrast, a method for measuring the amount of residual pig iron, based on the same idea as dilution analysis by RI, was established, making it possible to measure the rate of hearth erosion and also estimate the proper time for relining. ${ }^{5), 6)}$

A steel pipe with a capsule enveloping a ${ }^{60} \mathrm{Co}$ wire was inserted through the tuyere peephole to charge the RI into the hearth, after which the hot metal was sampled at intervals of 3 to $5 \mathrm{~min}$ for 4 taps to measure its radioactivity and calculate the amount of residual pig iron by the following formula:

$$
I_{1} \cdot w_{0}=\sum_{1=2}^{4} I_{i} \cdot W_{i}+I_{4}^{\prime} \cdot w_{0}
$$

where,

$w_{0}$ : amount $(\mathrm{t})$ of residual pig iron

$I_{1}$ : last radioactivity $(\mathrm{cpm})$ of the 1 st tap

$I_{i}$ : average radioactivity $(\mathrm{cpm})$ of the i-th taps after standard tap

$W_{i}$ : pig iron amount $(\mathrm{t})$ of the $\mathrm{i}$-th tap after standard tap

$I_{4}^{\prime}$ : last radioactivity $(\mathrm{cpm})$ of 4 taps.

Graphic representation of this relationship between the amount of residual pig iron and cumulative amount of pig iron made it possible to estimate the amount of erosion by the kind of hearth brick. It was revealed that carbon brick in the hearth eroded at the rate of about $10 \mathrm{~m}^{3}$ and chamotte brick of about $22 \mathrm{~m}^{3}$ for each $1000000 \mathrm{t}$ of pig iron tapped. This was so in ordinary pressure operations.

From the measured amounts of residual pig iron immediately before blowing out and immediately after blowing in, the state of hearth brick erosion at blowing out, and the design volume of hearth, it is possible to estimate the dead space of the hearth below the taphole. Trial calculations made in this connection give the dead space at $69 \%$ for the ordinary-pressure operation and at $52 \%$ for high-pressure process. This fact suggests that the effective hearth volume is increased by the high-pressure operation.

As it has become possible, moreover, to estimate the state of hearth erosion by measuring the amount of residual pig iron, this state has become a basis for determining the position of temporary tapholes to be opened at the flowing out of a blast furnace, salamander has ceased to remain at the time of relining, and it has become possible to shorten the time required for relining.

\section{Study on the Behavior of Fuel Oil Sulfur in Blast Furnace by Radioisotope ${ }^{35} \mathrm{~S}^{7}$}

In recent years, it is a common practice in blast furnace plants to inject fuel oil into the blast furnace. Fuel oils, however, contain sulfur which has the effect of increasing the sulfur content of pig iron manufactured. Therefore, low-sulfur fuel oils are generally used with due consideration being paid to the sulfur content in iron ore, coke, and other burden materials.

To clarify the behaviour of fuel oil in the blast furnace, fuel oils containing radioisotope ${ }^{35} \mathrm{~S}$ were injected into No. 2 Blast Furnace in Muroran Works and No. 1 and No. 2 Blast Furnaces in Hirohata Works. Radioactive sulfur ${ }^{35} \mathrm{~S}$ used was in the state of elementary sulfur in benzene solution or benzyl-mercaptan solution. It was added into and mixed evenly with 160 to $200 l$ of fuel oil by compressed air bubbling, and the radioactive fuel oil thus created was mixed into the fuel oil in the main pipe at a fixed flow rate of 10 to $12.5 l / \mathrm{hr}$ by Multon-Roy pump. The mixture went into the blast furnace through the blast tuyeres. This radioactive fuel oil injection was continued for about $16 \mathrm{hr}$ running. For this period and for several subsequent taps, the pig iron, slag, dust, top gas, etc., were sampled respectively.

In all these samples, the radioactive sulfur was in the state of precipitated barium sulfate, and radioactivity was determined by use of a low background automatic counter.

The following results were obtained:

(1) Specific radioactivity of pig iron and slag attained nearly constant values in nine to ten hours after the start of fuel oil injection with the radioactive sulfur.

(2) The ratio of the distribution ratio $(\mathrm{S}) / \mathrm{S}$ for fuel oil sulfur to that for other blast furnace burden was approximately 1.2 , indicating that desulfurization rate is slightly better in fuel oil sulfur than in those of other burden materials.

(3) In order to keep the sulfur of pig iron within a certain value, it is necessary either to use fuel oil of lower sulfur content or restrict the quantity of fuel oil injected.

\section{Sintering}

${ }^{60} \mathrm{Co}$ of equal grain size to fine ore or fine ore marked after submerging in a RI containing liquid is used for study of the mixed condition of sinter material, measurement of the staying time of fine ore in the balling drum, study of the pelletizing condition, etc. ${ }^{8)}$

Also reported are the use of gamma-ray density gauges in evaluating the sintered conditions and other applications. ${ }^{9)}$

\section{Moisture Measurement of Sinter Materials and Blast Furnace Coke by Neutrons}

Neutron moisture gauges were developed which utilize the fact that the slow down power of neutrons emitted from ${ }^{226} \mathrm{Ra}-\mathrm{Be},{ }^{241} \mathrm{Am}-\mathrm{Be}$, etc., is nearly proportional to the number of hydrogen atoms, and their 
application to the moisture measurement of sinter materials and blast-furnace coke was studied. ${ }^{10}$ )

As a result, rapid automatic measurement, and automatic control also, were found practicable, and are already in extensive use.

There are two forms of detection procedure available, the insertion type and the surface type, which should be selected according to the place and conditions of use.

As the neutron source, ${ }^{241} \mathrm{Am}-\mathrm{Be}$ is used recently by reason of safety.

\section{Level Gauges}

${ }^{60} \mathrm{Co}$ has come into use for the detection of furnace top burden levels, ${ }^{11), 12)}$ but not yet to the extent of being substituted for the older sounding rod system.

Also for the detection of dust levels in various ore bins and dust catchers, gamma-ray level gauges are already coming into use. Equipment of this sort is expected to find increasing applications in the coming years.

\section{Interlock System for Coke Oven Pushers}

An accident control system consisting of a ${ }^{60} \mathrm{Co}$ gamma-ray source located in the coke guide car and a detector placed on the coke pusher side so that the pusher might work only upon detection of radiation was installed about two years ago and has been smoothly operating ever since. ${ }^{13)}$ The system is outlined in Fig. 1.

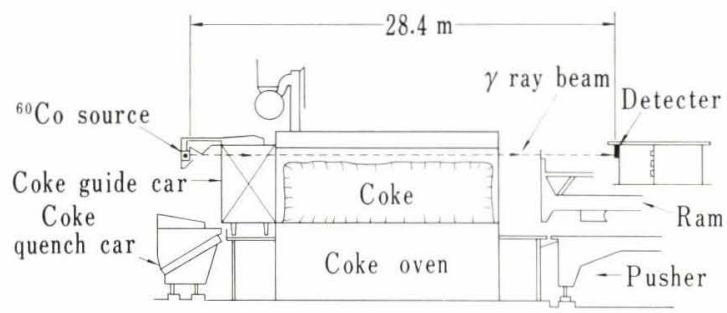

Fig. 1. Interlock system of coke oven pusher by $\gamma$ ray

\section{Refractories}

Identifying the erosion process of refractories is essential to furnace operations and to the improvement of furnace materials. In the past, measurement of the condition of erosion was impossible in the course of furnace operation because the high temperature level of the places where refractories were used made such measurement possible only in a cooled state of the furnace at the time of relining. The use of RI, however, has made this measurement possible.

This method is applicable in two forms; the one is to embed ${ }^{60} \mathrm{Co}$ or the like in the designated position of the refractory, identify the presence or absence of RI from outside the furnace during operation by detector, and thereby ascertain the time of refractory fusion damage; the other, as adopted when outside detection is difficult, is to sample the hot metal or molten steel during operation and ascertain the time of fusion damage by the presence or absence of radioactivity in the samples. ${ }^{14}$ )
Measurement of lining wear in the blast furnace shaft and bosh has been in practice already since several years ago. ${ }^{15)-17)}$

Also under measurement is the state of erosion in ladle brick, ${ }^{18}$ ) hot-metal mixer brick, open-hearth furnace brick, and converter brick, ${ }^{19)}$ the practice with some circles being to determine relining days by the presence or absence of RI.

\section{Steelmaking}

The utilization of RI in this field is prominent, with a great many research reports made and the use of RI becoming an indispensable means of detecting the movement of molten steel, the solidification of metals, the behavior of deoxidizers, the tracing of nonmetallic inclusions in steel, etc. Studies in this category are expected to increase more and more in the future.

\section{The State of Molten Steel Circulation in R-H Vacuum Degasser}

As a means of steel quality improvement, vacuum degassing equipment is being adopted of late, and at our works, too, a Ruhrstahl degasser has been installed.

This equipment, as illustrated in Fig. 2, is such that the two dipping legs attached to the bottom of the vacuum degassing vessel are immersed in the molten steel in the ladle to provide degassing while circulating the molten steel between the vacuum vessel and the ladle.

In this equipment, it is operationally indispensable to identify the circulating speed of the molten steel and the mixed condition of the molten steel in the ladle.

For this measurement, an injecting steel rod encapsuling ${ }^{198} \mathrm{Au}$ at the tip was inserted into the bottom of the up-leg and a water-cooled detector connecting to a rate meter and a recorder was placed on the downleg to measure the radioactivity.

This shed light on the relationship of argon gas blow-in rate to circulating rate and on the motion of the molten steel in the ladle, thus proving the mixing of the molten steel in this equipment to be very satisfactory. ${ }^{20), 21)}$

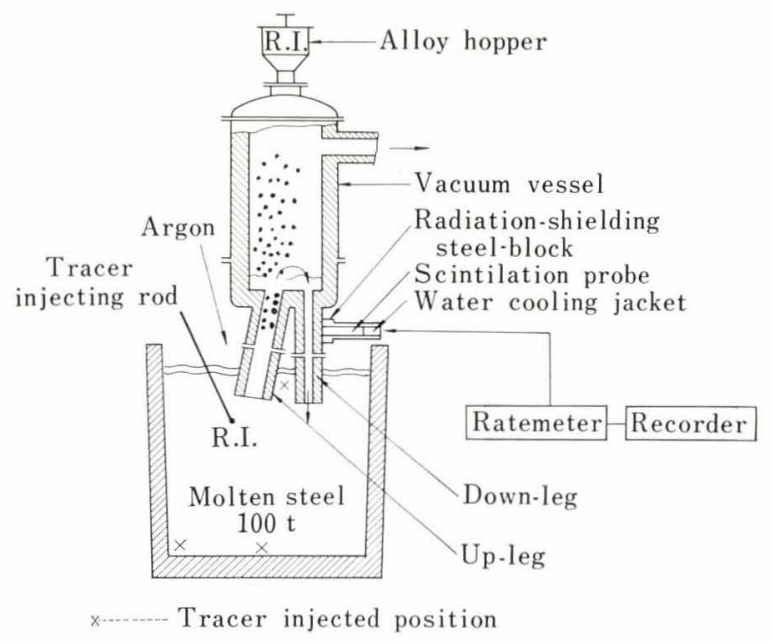

Fig. 2. R-H degasser and radioactive detector 


\section{Studying the Mixed Condition of Hot Metal in Hot- metal Mixer}

For the automatic control of L-D converter operation, it is necessary to identify changes in the composition of hot metal sent from the blast furnace, therefore it was studied whether the hot metal was sufficiently mixed in the hot-metal mixer $(1200 \mathrm{t})$.

${ }^{60} \mathrm{Co}$ or ${ }^{198} \mathrm{Au}$ was put into the hot-metal ladle. The hot metal holding the RI evenly melted at the time of tapping from the blast furnace was charged into the hot-metal mixer. The hot metal was sampled at the slag outlet of the mixer at given intervals of time and also subsequent taps of the hot metal from the mixer were sampled for determination of radioactivity to estimate the mixed condition of the hot metal.

This revealed that the hot metal charged into the mixer spread over the surface layer of the older metal in the mixer, reached the taphole in 1 to 2 min after being charged, and took 90 to $120 \mathrm{~min}$ to mix with the older metal in the mixer. Namely, it turned out that the hot metal charged did not immediately mix with the older metal in the mixer but lie spreading afloat over the top of the older metal.

Model experimentation found this to arise from a density difference caused by a hot metal temperature difference. ${ }^{22,23)}$

\section{The Melting Rate of Cold Pig Iron and Scrap in Con- verter}

In the L-D steelmaking process, a certain amount of scrap and cold pig iron is charged at the same time with a large amount of hot metal. These scrap and cold pig iron may be charged in varying proportions according to the economic situation, process fluctuations in the steelworks, and to other factors.

With an increased charge of scrap and cold pig iron, complete melting may not occur in a short time of blowing as done in the L-D steelmaking process, the nonmelting may bring about a change in the composition of the steel tapped, and this may result in failure to meet the specified composition requirements.

Therefore, with a view to learning the charge limits of scrap and cold pig iron applicable under the ordinary blowing conditions of the $60 \mathrm{t}$ converter, radioactive dilution analysis was carried out to determine the melting rate of scrap and cold pig iron.

1. Procedure for Measurement of the Scrap Melting Rate

${ }^{60} \mathrm{Co}$ was put into the hot metal being taken out of the hot-metal mixer into the ladle. The hot metal was reladled to charge into the converter the hot metal containing RI evenly mixed. The molten steel and slag in the converter were sampled during blowing to measure their radioactivity. The process through which the radioactivity of the hot metal was diluted by the melting of the scrap was traced to determine the scrap melting rate.

Because the specific radioactivity of ${ }^{60} \mathrm{Co}$ contained in the hot metal changes with the progress of blowing owing to the melting of the scrap, the oxidation loss of the five elements and iron in the hot metal, the transfer of ${ }^{60} \mathrm{Co}$ to the slag or dust, etc., the scrap melting rate,
$K_{s}(\mathrm{t})$, was calculated from the following formula based on the material balance of ${ }^{60} \mathrm{Co}$ :

$$
\begin{aligned}
K_{s}(\mathrm{t}) & =\left[K-\left\{W_{s g}(\mathrm{t}) \operatorname{Asg}(\mathrm{t})+W(\mathrm{t}) A s(\mathrm{t})\right.\right. \\
& \left.\left.+\int A_{d}(\mathrm{t})\left(d W_{d}(\mathrm{t}) / d t\right) d t\right\}\right] / A s(\mathrm{t}) W_{s c}
\end{aligned}
$$

where,

$$
\begin{aligned}
& \text { Wsg: weight of slag } \\
& W \text { : weight of hot metal } \\
& W_{d} \text { : weight of dust } \\
& \text { Wsc: weight of scrap } \\
& \text { Asg: specific radioactivity of slag } \\
& \text { As: specific radioactivity of molten steel } \\
& A_{d} \text { : specific radioactivity of dust } \\
& K \text { : constant. }
\end{aligned}
$$

In this case, converter blowing was carried out without the use of cold pig iron.

\section{Procedure for Measurement of the Cold Pig Iron Melt-} ing Rate

In contrast to the case of $I V$. 3. $1 .,{ }^{60} \mathrm{Co}$ was charged into the ladle during tapping in the blast furnace to prepare a cold pig iron containing ${ }^{60} \mathrm{Co}$ and the pig iron was used in the converter to study how the iron melted during blowing.

$K_{p}$, the melting rate of the iron, was calculated by the following formula as in the case of $I V, 3.1$ :

$$
\begin{aligned}
& K_{p}(\mathrm{t})=\frac{1}{W c p[A-A s(\mathrm{t})]} \times[A s(\mathrm{t}) W(\mathrm{t}) \\
& +A s(\mathrm{t}) W s c \cdot K_{s}(\mathrm{t})+W_{s g}(\mathrm{t}) A s g(\mathrm{t}) \\
& \left.+A W_{c p}+\int^{\mathrm{t}} A_{d}(\mathrm{t})\left(d W_{d}(\mathrm{t}) / d t\right) d t-K^{\prime}\right]
\end{aligned}
$$

where,

$$
\begin{aligned}
A: & \text { specific radioactivity of cold pig iron } \\
W_{c p}: & \text { weight of cold pig iron } \\
K^{\prime}: & \text { constant. }
\end{aligned}
$$

3. Procedure for Simultaneous Measurement of the Melting Rate of Scrap and Cold Pig Iron by Double Tracer Method

Cold pig iron evenly containing ${ }^{60} \mathrm{Co}$ and ordinary scrap were charged into the converter, in addition to which hot metal holding molten ${ }^{198} \mathrm{Au}$ was charged for blowing. Sampling was carried out in the same manner as described in the section $I V$. 3. 1. and measurement was repeated with consideration for the half life of ${ }^{198} \mathrm{Au}$, separating the counts of ${ }^{198} \mathrm{Au}$ and ${ }^{60} \mathrm{Co}$ to calculate $K_{s}$ and $K_{p}$ from the balances of ${ }^{60} \mathrm{Co}$ and ${ }^{198} \mathrm{Au}$. An example of the test results is given in Fig. 3.

While the cold pig iron finished melting in about 10 min from the start of blowing, the scrap melted $50 \%$ in about $15 \mathrm{~min}$ and tended thereafter to melt rapidly as the hot metal temperature rose. ${ }^{24)}$

\section{The Mixed Condition in Ladle of Alloys Added at Tapping from Converter}

In the making of high-grade steels, ferroalloys are added at the time of tapping from the converter into the ladle. In this operation, improper timing and ladle position for ferroalloy additions will bring about a nonuniformity of molten steel composition in the ladle, particularly an increased variation of additional elements between steel ingots in the following process, and create a cause of rejection for the finished steel plates. 


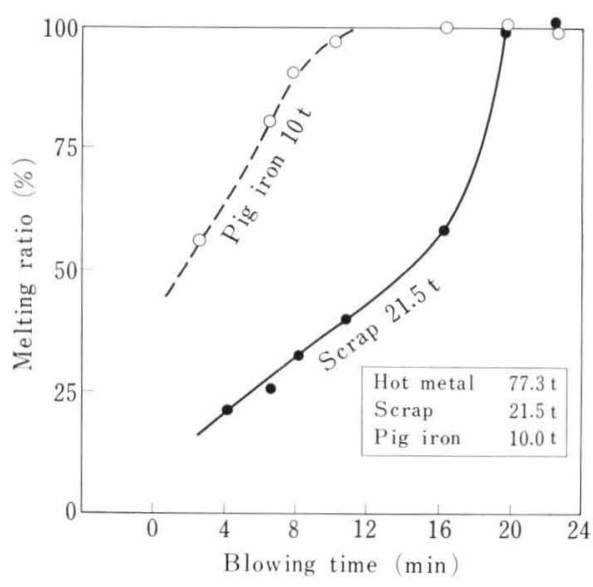

Fig. 3. Results of double tracer method

Another steelmaking practice is to hold the ladle for some time after tapping, for the purpose of uniforming the molten steel composition and floating the nonmetallic inclusions, but its effects are yet to be determined.

Therefore, in order to study the mixed condition in ladle of Si-Mn alloy used in the greatest amount among the ferroalloys and the effects of the ladle holding time, RI-containing Si-Mn alloy was prepared and added into the ladle during tapping to sample the molten steel during ingot casting for measurement and testing of its radioactivity.

The RI added consisted of $10 \mathrm{Si}-\mathrm{Mn}$ alloy units $(50 \times 40 \times 50 \mathrm{~mm})$ having a ${ }^{60} \mathrm{Co}$ pellet $(100 \mu \mathrm{Ci})$ embedded into a $3 \mathrm{~mm}$ dia. hole bored at the center of each unit, of ${ }^{60} \mathrm{Co}$ evenly melted in the Si-Mn alloy at the time of its manufacture (Kanazawa Works, Japan Electrical Industries), and of ${ }^{59} \mathrm{Fe}$ prepared by irradiation of electrolytic iron and enclosed in a steel capsule.

The RI were added into the ladle at various stages from the initial to closing periods of tapping and after the completion of tapping. Insertion of the RI after tapping was carried out with the ${ }^{59} \mathrm{Fe}$ capsule attached to the tip of a steel rod.

Experimentation was performed in two forms, the one being to pour immediately upon transfer of the ladle to the casting platform after tapping and the other to cast with a holding time taken of the ladle. Sampling was done after tapping, at the temperature measuring deck from the top of the ladle and at the casting platform at the beginning and close of casting for each ingot. The samples for determination of radioactivity measured $15 \mathrm{~mm}$ in dia. and $30 \mathrm{~mm}$ in length and were measured with a scintillation counter.

The measurement disclosed that in case of the RIcontaining Si-Mn alloy charged in to the ladle between 20 and $75 \%$ tapping of the molten steel, the RI was mixed evenly enough, the specific radioactivity of the RI being equal for individual ingots, but that in case of the RI-containing Si-Mn alloy charged between 90 and $95 \%$ tapping of the molten steel, the molten steel composition in the ladle was not uniform, an unusually high level of radioactivity being detected

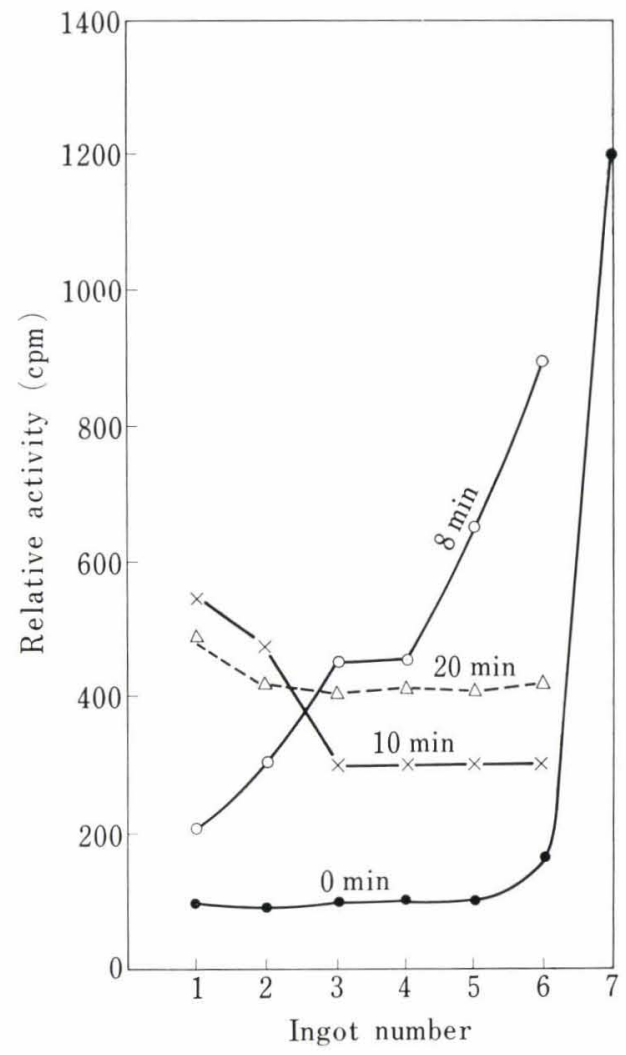

Fig. 4. Effect of holding time in the ladle

in the molten steel of the last ingot or ingot for scrap.

Next, the Si-Mn alloy was charged at 95\% tapping of the molten steel and after completion of tapping the ladle holding time was varied. An example of the test results is given in Fig. 4. The test revealed that when the holding time was zero minute the alloy added was not sufficiently mixed, a very dense RI layer being segregated in the ingot for scrap, but that as the holding time lengthened the density variation between individual ingots diminished and that a holding time of over $10 \mathrm{~min}$ provided after tapping was effective in uniforming the molten steel composition. ${ }^{25)}$

\section{The Distribution of Inclusions from Graphite-silicon Stools for Ingot Making}

Of recent years a so-called graphite stool constructed chiefly of graphite and silicon carbide is used in the part where the molten steel falls, with a view to stool protection during ingot making. In the case of killed steel for plate, however, it comes into question whether nonmetallic inclusions arising from this graphite stool will affect the occurrence of product defects. In order to clarify this question, ${ }^{140} \mathrm{Ba}$ was incorporated into graphite stool and repair-purpose graphite mortar for study from various angles.

A graphite stool having a ${ }^{140} \mathrm{BaCl}_{2}$ solution added at the time of fabrication to incorporate the RI into a $30 \mathrm{~mm}$ surface layer of the stool was fabricated and used during ingot making.

For the repair-purpose graphite mortar, a ${ }^{140} \mathrm{BaCl}_{2}$ solution was diluted in water containing a small amount of water glass and the dilute was poured on the gra- 
phite castable to be mixed.

Shown in Fig. 5 is an example of radioactivity measurement on the surface of a slab rolled from ingot from the graphite stool containing ${ }^{140} \mathrm{Ba}$. Portable scintillation counter was used in the measurement.

The distribution of ${ }^{140} \mathrm{Ba}$ was found limited to the bottom of the ingot which was in direct contact with the graphite stool.

Experimentation with ${ }^{140} \mathrm{Ba}$ charged into the repairpurpose mortar, however, detected highly radioactive areas not only in the bottom but also other parts of the ingot. Supersonic flaw detection mode of this slab disclosed that the distribution of radioactivity did not necessarily agree with supersonic defect testing results. ${ }^{26)}$

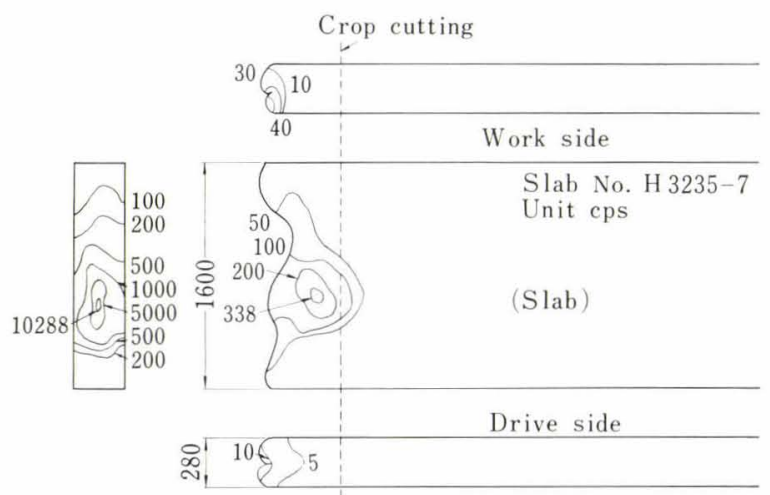

Fig. 5. Distribution of ${ }^{140} \mathrm{Ba}$ on slab surface

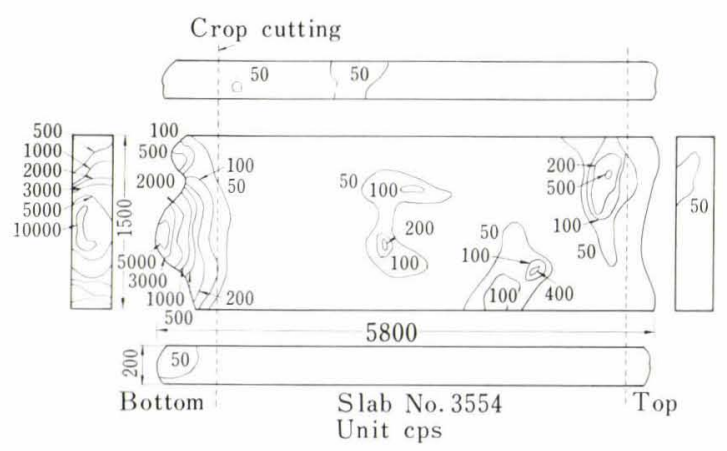

Fig. 6. Distribution of ${ }^{140} \mathrm{Ba}$ on slab surface

\section{On the Behaviour of Reducing Slag in Electric Furnace}

The radioactive lime $\left({ }^{45} \mathrm{CaO}\right)$ were added in the reducing slag of $60 \mathrm{t}$ electric furnace. Radioactivity in the macroscopic inclusions extracted from the killed steel ingot with slime method were measured. $\mathrm{CaO}$ (mean $4.7 \%$ ) in macroscopic inclusions in killed steel are originated from the reducing slag in electric furnace process by 50 to $70 \%$. The amount of inclusion from slag in molten steel are reduced by $40 \%$ during holding the ladle in 10 min after tapping. ${ }^{27)}$

\section{The Casting of Steel Ingots}

Various questions related to the movement and solidification of molten steel in ingot molds are explained from results of radiography as conducted with an X-ray film applied to the ingot into which RI was incorporated at proper time and which was cut after it solidified. ${ }^{28)}$

The authors added the radioisotope tracer ${ }^{59} \mathrm{Fe}$ in $6 \mathrm{t}$ killed steel ingots at adequate time intervals after teeming. From those studies, the formation of "mushy zone " at the lower part of ingot during the earlier stage of ingot solidification was proved, and the velocity of the convective flow along the solidification wall was calculated from the autoradiography. ${ }^{29)}$

\section{The Behaviour of Addition Elements}

The behaviour of elements added in the course of steelmaking and ingot making is identified by two different methods: the one is the direct addition of RI to ascertain the distribution of the metals by radiography of ingot sections; the other is after-irradiation analysis in which, instead of adding RI, test pieces are collected from the ingot section and irradiated in a nuclear reactor to determine from their radiography the distribution of the addition elements. Both methods are applied in various ways. ${ }^{30), 31)}$

\section{Rolling}

In the field of rolling, RI are used less as tracers although they find very extensive applications as measuring aids such as gamma-ray thickness gauges for plate, X-ray thickness gauges and gamma-ray thickness gauges for hot strip and cold strip, gamma-ray thickness gauges for cold rolled sheet, beta-ray thickness gauges for thin plate, and beta-ray film thickness gauges for zinc-coated and tin-coated plate and sheet.

\section{Study of Metal Flows in the Slab Rolling Process ${ }^{32), 33)}$}

For the study of metal flows in the hot rolling process, the method was formerly adopted of including a foreign material in a billet and observing the billet after it has been rolled, but it is little used today because of difficulty in locating the included material. In contrast, RI can be easily located even if it is very small in size, so that we inserted RI pellet into specified positions of a steel ingot, and examined the metal flow in the slab rolling process.

\section{Testing Method}

Metallic cobalt grains measuring $1 \mathrm{~mm} \phi \times 1 \mathrm{~mm}$ were irradiated in a nuclear reactor to prepare ${ }^{60} \mathrm{Co}$ pellets rated at $1-10 \mu \mathrm{Ci}$ apiece for use in the experiment.

The steel ingot, a mass of low-carbon rimmed steel weighing about $13 \mathrm{t}$, was perforated at specified places as illustrated in Fig. 7; the ${ }^{60} \mathrm{Co}$ pellets were inserted into the holes and the holes were sealed with round bar; the surface of the ingot was welded.

The test ingot with the ${ }^{60} \mathrm{Co}$ included was heated in a soaking pit and rolled according to the usual rolling schedule. The slabbing mill was a reversible 2-high universal type, with a horizontal roll of $1150 \mathrm{~mm} \phi$ and a vertical roll of $923 \mathrm{~mm} \phi$. After rolling, the slab was left to cool and the travel positions of ${ }^{60} \mathrm{Co}$ were measured by a scintillation counter equipped with a collimator. For accurate location of the ${ }^{60} \mathrm{Co}$ deep in the slab, the slab was cut by fusion to 
determine the interior ${ }^{60} \mathrm{Co}$ positions in combination with measurement from the slab surface. For close location of the RI, moreover, radiography by X-ray film was used also.

\section{Results of Metal Flow Measurement}

The results of measurement on the slabbing metal flow of the ingot shown in Fig. 7 are given in Fig. 8.

In the slab surface, the location of ${ }^{60} \mathrm{Co}$ could be measured very simply.

Use of the RI permitted the metal flow to be traced easily in actual operations and enabled us to learn how metal flow behaved in the hot rolling process.

Given in Fig. 9 is an example of experimental results on slabs rolled from the same ingot with varied vertical roll drafts, or on fish tail differences owing to slab width variations.

\section{Metal Flow in the Rolling of Sheet Piles ${ }^{34)}$}

Because of the special shapes of sheet piles used in civil engineering, clarifying the positional relationships in the rolling process from ingots through semi-finished beam blanks to finished products is indispensable both for obtaining finished products of satisfactory shape and for studying the causes of flaws.

${ }^{60} \mathrm{Co}$ pellets were included into specified places in the top, middle, and bottom of the ingot; the RI was located for the beam blank after blooming and the blank as such was rolled on a larger scale; the RI was located for the finished sheet pile; and their respective metal flows were studied. An example of the experimental results is given in Fig. 10.

These results clarified the ingot-to-production positional relationships, which proved very effective not only in roll design but also in detecting the causes of defects (Fig. 11).

\section{Tracer Testing of Slab Surface Defects ${ }^{35}$}

To trace the causes of product defects occurring in cold rolled sheet and diminish the surface defects is vital to the attainment of higher yields.

Causes of product defects may be classified into intrinsic ones dependent on steclmaking and ingot making conditions and into extraneous ones dependent on mechanical factors such as heating, rolling, and transportation. These defect causes, however, may sometimes interact and it is extremely difficult to define them.

As an initial step of investigation on the product defects, therefore, in order to study whether slab surface defects would become defects in hot coil and cold coil, the slab surface defect positions were marked by RI and traced down to the sheet stage.

Furthermore, artificial defects were produced on the slab surface, the defect positions were marked by RI and traced down to the product stage, and the condition of defect change in the rolling process was studied.

This made it possible to carry out tracer testing with great simplicity as compared to the older methods.

\section{Surface Treatment}

The oil used for lubrication or cooling inevitably

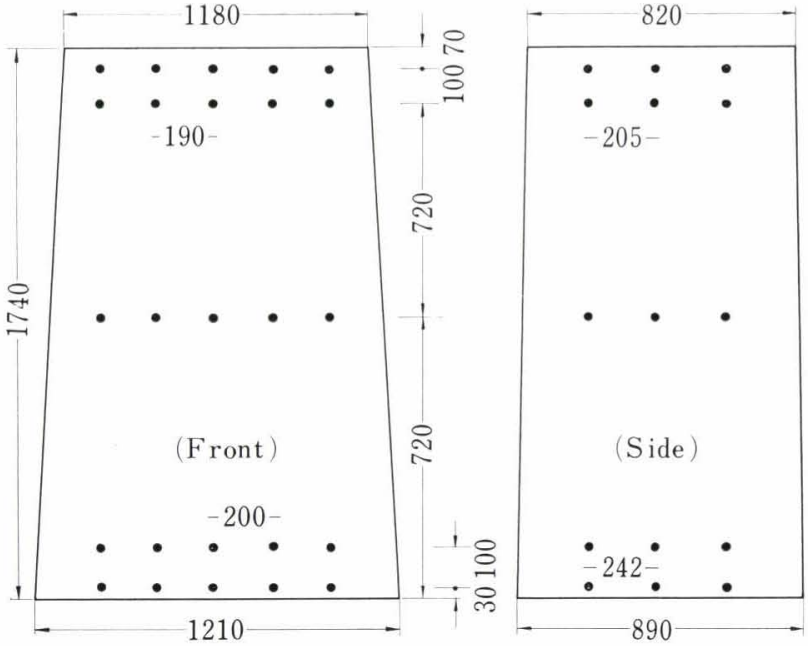

Fig. 7. Inserted position of ${ }^{60} \mathrm{Co}$ in the test ingot

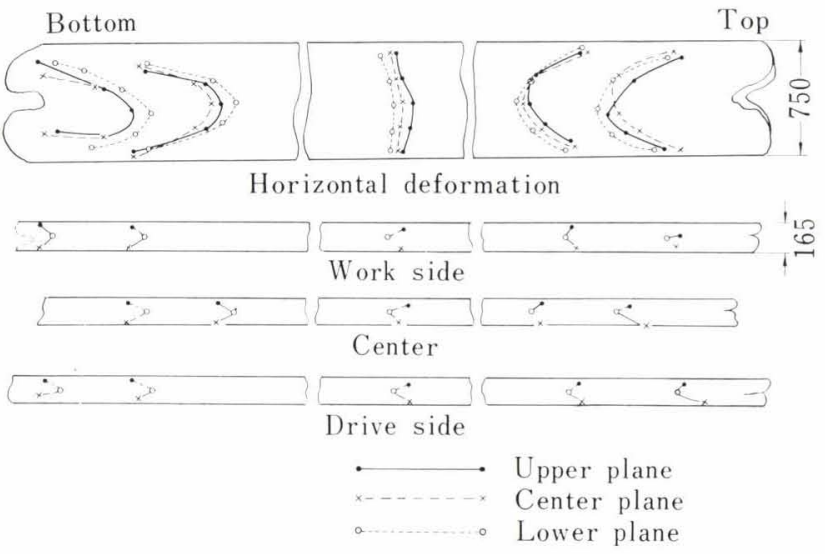

Fig. 8. Plastic deformation of ingot in universal blooming mill process
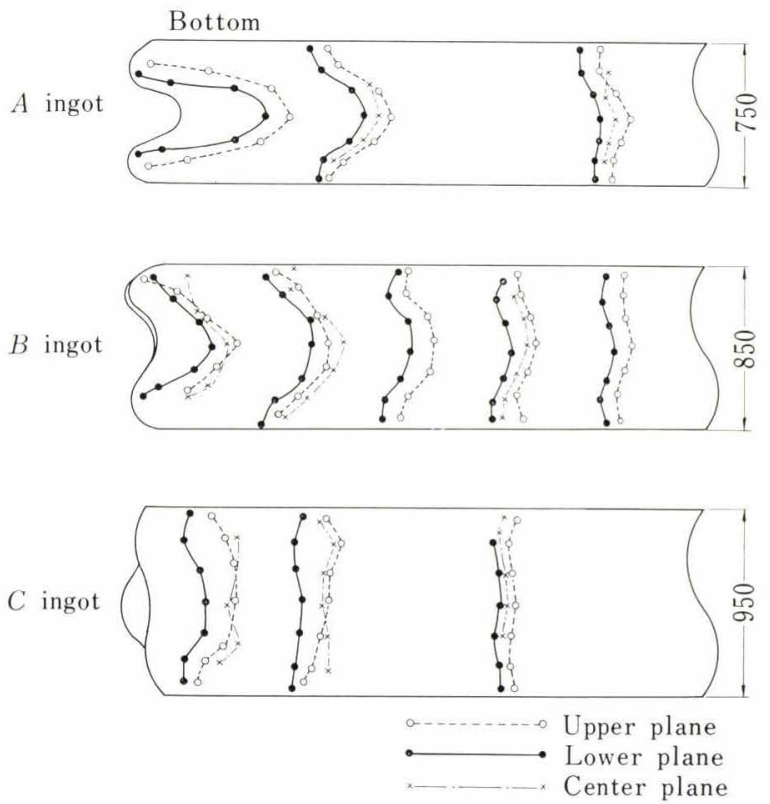

Fig. 9. Plastic deformation of ingot bottom

remains on the surface of cold-rolled sheets, and this 

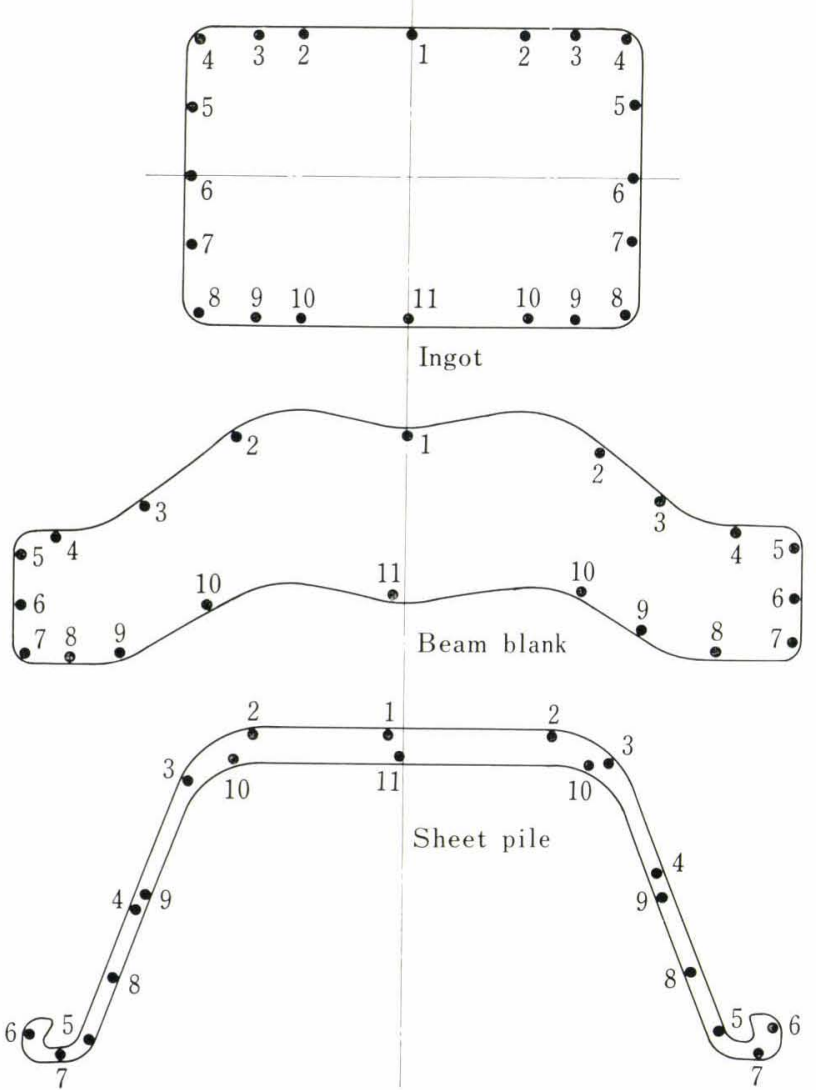

Fig. 10. Sectional diagram of metal flow

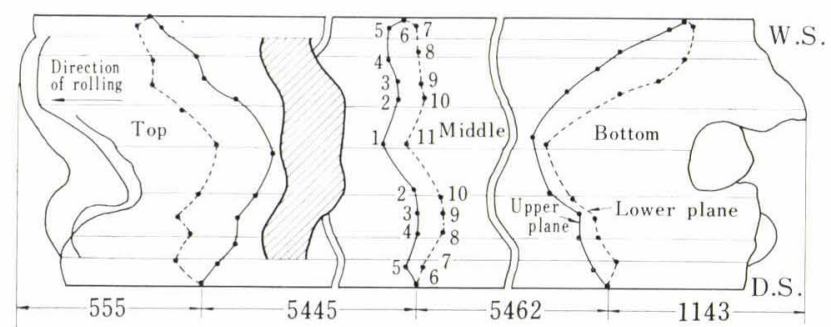

Fig. 11. Metal flow of beamblank (plane)

oil exerts various effects on the following process. Also electrolytic cleaning and pickling are carried out as preliminary treatment to the plating process. To determine whether these degreasing processes are adequate or not, research utilizing RI is undertaken.

Mori and Taira ${ }^{36)}$ reported the results of cleaning tests with ${ }^{35} \mathrm{~S}$-containing palm oil, in which steel sheet samples coated with ${ }^{14} \mathrm{C}$ (stearic acid) were used to evaluate detergents, surface active agents, and electrolytic cleaning conditions.

Sudo and Morimoto ${ }^{37)}$ reported results of alkaline electrolytic cleaning experiments with a sodium phosphate bath based on ${ }^{32} \mathrm{P}$ and with a sodium orthosilicate bath based on ${ }^{14} \mathrm{C}$ (palm oil containing stearic acid).

Likewise, in an effort to determine steel sheet cleaning effects, we carried out tests using radiocolloids of ${ }^{60} \mathrm{Co}(\mathrm{OH})_{2}$ prepared by heating and dissolving ${ }^{60} \mathrm{Co}$ with an acid agent and neutralized with an alkaline agent. ${ }^{38)}$
On the oxide formation in chromium plating and chemical treatment of chromium-type Tin Free Steel, we carried out the tests in Sargent bath and chromate solution using ${ }^{51} \mathrm{Cr}$ as a tracer. ${ }^{39)}$

\section{Conclusion}

Application of radioisotope at the steelworks has been described chiefly on the basis of the result we have carried out, but there are many areas where radiations remain to be utilized, and the authors are convinced that they will find increasing applications not only in process experiments but also in research in the iron and steel industry.

The use of radiations is not yet extensive, for it always involves radioactivity risks and sheer prejudice against it persists in some form or other. Since suitable steps can eliminate such risks, however, the authors hope that extensive applications will get under way in all fields.

\section{REFERENCES}

1) K. Miyagawa, H. Isshiki, and I. Mishima: Tetsu-to-Hagané, 51 (1965), 1742.

2) I. G. Polovchenko: Stal, 12 (1957), 1057.

3) M. Serizawa, Y. Takahashi, K. Kanbara, and K. Miyagawa: Tetsu-to-Hagané, 44 (1958), 1251.

4) Y. Jomoto, T. Yonezawa, K. Miyagawa, and T. Hagiwara: Tetsu-to-Hagané, 51 (1965), 696.

5) K. Miyagawa, H. Isshiki, and I. Mishima: Tetsu-to-Hagané, 51 (1965), 1742.

6) K. Miyagawa and H. Isshiki: Tetsusto-Hagané, 52 (1966), 336.

7) K. Kusuno, S. Shimada, Y.Jomoto, Y. Kanayama, S. Otabe, M. Yasunaga, K. Miyagawa, I. Ichijima, and H. Isshiki: Technical Report of Fuji Steel, 16 (1967), 211.

8) H. Mori, M. Mathuo, I. Hanaki, T. Takemura, and H. Mizutani: Tetsu-to-Hagané, 49 (1963), 1279.

9) Shimada, M. Mitsutsuka and M. Yamate: Tetsu-to-Hagané, 47 (1961), 1307.

10) K. Miyagawa, I. Mishima, T. Takeda, and Y. Tanabiki: Technical Report of Fuii Steel, 16 (1967), 247.

11) L. R. Stone: Blast Fur. E Steel Plant, (1966), 1121.

12) M. Shimada, M. Mitsutsuka, and M. Yamate: Tetsu-toHagané, 50 (1964), 390.

13) K. Miyagawa and K. Fujita: Cokes Circular, 14 (1965), 150.

14) K. Miyagawa and H. Isshiki: Proceedings of the 7 th Conference on Radioisotopes, (1966), 167.

15) A. Tominaga, T. Yatsuzuka, and S. Shono: Proceedings of the 2nd Conference on Radioisotopes, (1969), 139.

16) A. Tominaga, T. Yatsuzuka, and S. Shono: Tetsu-toHagané, 46 (1960), 7.

17) S. Hayashi, G. Suzuki, H. Iijima, T. Yamaguchi, and T. Kobayashi: Tetsu-to-Hagané, 46 (1960), 1098.

18) K. Miyagawa, T. Ochiai, J. Ikeda, and H. Isshiki: Tetsu-toHagané, 50, (1964) 1799.

19) K. Miyagawa and H. Isshiki: Proceedings of the 7th Conference on Radioisotopes, (1966), 167.

20) S. Watanabe, H. Watanabe, K. Asano, M. Nakayama, K. Miyagawa, and E. Nomura: Tetsu-to-Hagané, 50 (1964), 1773.

21) K. Miyagawa, E. Nomura, Z. Nozaki, T. Adachi, T. Kishida, and K. Morii: Tetsu-to-Hagané, 53 (1967), 302.

22) K. Miyagawa, E. Nomura, I. Mishima, E. Honma, and I. Furugaki: The 1st Annual Meeting on Radioisotopes in the Physical Sciences and Industry, (1964), 48. 
23) H. Mori and M. Matsuo: Tetsu-to-Hagané, 49 (1963), 1396.

24) K. Miyagawa, E. Nomura, T. Ooya, I. Furugaki, H. Matsunaga, and T. Tominaga: Tetsu-to-Hagané, 51 (1965), 1925.

25) K. Miyagawa, S. Ookubo, E. Nomura, T. Tominaga, and T. Mori: Tetsusto-Hagané, 52 (1966), 440.

26) K. Miyagawa, E. Nomura, R. Arima, and M. Katagami: Tetsusto-Hagané, 51 (1965), 1967.

26) K. Miyagawa, E. Nomura, R. Arima, and M. Katagami: Tetsu-to-Hagané, 51 (1965), 1967.

27) K. Miyagawa, K. Asano, E. Nomura, and M. Nisida: Tetsu-to-Hagané, 54 (1968), 872.

28) H. Mori, etc.: Tetsu-to-Hagané, 50 (1964), 1754; 1848, $\mathbf{5 1}$ (1965), 1879; 1973, 52 (1966), 419; 1552, 53 (1967), 377.

29) K. Miyagawa, E. Nomura, T. Mitsuo, T. Horigome, and M. Kitamura: Tetsu-to-Hagané, 55 (1969), 139.

30) K. Narita, M. Taniguchi, and A. Kujima: The 1st Annual Meeting on Radioisotopes in the Physical Sciences and Industry, (1964), 52.

31) K. Narita and M. Taniguchi: Kobe Steel Engineering Reports, 17 (1967), 280.
32) K. Saeki, M. Kozaki, A. Yoshimochi, K. Miyagawa, and E. Nomura: Tetsu-to-Hagané, 52 (1966), 616; J. of Japan Society for Technology of Plasticity, 8 (1967), 152.

33) K. Miyagawa, M. Kozaki, A. Yoshimochi, and E. Nomura: Tetsu-to-Hagané, 54 (1968), 137.

34) Y. Yamamoto, A. Yoshimochi, K. Miyagawa, E. Nomura, and T. Egashira: Tetsu-to-Hagané, 53 (1967), 387.

35) K. Miyagawa, I. Mishima, and T. Egashira: The 4th Annual Meeting on Radioisotope in the Physical Sciences and Industry, (1967), 93.

36) H. Mori and T. Taira: Yawata Technical Reports, 231 (1961), 3051.

37) E. Sutou and H. Morimoto: Technical Report of Toyo Kohan Co., Ltd., (1963), 65.

38) K. Miyagawa and I. Ichijima: The 4th Annual Meeting on Radioisotopes in the Physical Sciences and Industry, (1967), 91.

39) H. Uchida, O. Yanabu, K. Miyagawa, T. Saitô, E. Nomura, T. Enari, and K. Doi: The Autum Meeting in the Japan Institute of Metals, (1968), 77. 